\title{
Revisiting Innovation Leadership
}

\author{
Hazaz Abdullah Alsolami ${ }^{*}$, Kenny Teoh Guan Cheng ${ }^{2}$, Abdulaziz Awad M. Ibn Twalh ${ }^{3}$ \\ ${ }^{1}$ Putra Business School, Universiti Putra Malaysia, Serdang, Malaysia \\ ${ }^{2}$ Faculty of Economics and Management, Universiti Putra Malaysia, Serdang, Malaysia \\ ${ }^{3}$ Iona College, New Rochelle, NY, USA \\ Email: "hazaz22@hotmail.com
}

Received 3 May 2016; accepted 6 June 2016; published 9 June 2016

Copyright (C) 2016 by authors and Scientific Research Publishing Inc.

This work is licensed under the Creative Commons Attribution International License (CC BY). http://creativecommons.org/licenses/by/4.0/

c) (i) Open Access

\begin{abstract}
Innovation leaders must possess multiple attributes in order to effectively manage the increasing demands for innovation in many facets of business organizations, especially in influencing creativity and innovation. Research findings have indicated that the behaviours of innovation leaders differ from the leadership behaviours that are deemed sufficient in conventional leadership situations. However, the literature on leadership suggests that there remains a research gap-what are the attributes required of successful innovation leaders?-That warrants a study to determine more precisely what those attributes are. A review of the current literature indicated that innovation leadership is a multi-leadership phenomenon consisting, inter alia, of charismatic leadership, transformational leadership and innovation leadership attributes and competencies. This paper discussed the innovation leadership attributes as portrayed in the literature, thereby providing a firm, structural foundation for researching the components of innovation leadership and providing insights to define the construct and, ultimately, to develop a psychometric measure.
\end{abstract}

\section{Keywords}

Contemporary Leaderships, Innovation Leadership, Innovation Leadership Attributes

\section{Introduction}

Research in management practices has placed great emphasis on the critical role of leadership in achieving an organization's vision and mission, and to face challenges especially during turbulent times (Chen, 2007; Samad \& Abdullah, 2012; Sattayaraksa \& Boon-Itt, 2012). Empirical studies have consistently postulated that leadership is one of the most important factors for organizational success (LeBrasseur, Whissell, \& Ojha, 2002; Samad, 2012; Seltzer, 1990).

${ }^{*}$ Corresponding author. 
Innovation leadership plays a multitude of roles when facilitating innovation in organizations and the role of leader is especially important in influencing creativity and innovation. With the appropriate leadership, successful innovation becomes a realistic and achievable goal; but without it, the challenge may prove insurmountable (Hunter \& Cushenbery, 2011). Senior and Fleming (2006) and Samad (2012) contend that there is no single leadership theory that is appropriate to all situations. Taking different perspectives, contemporary scholars have proposed various theories. This study focuses on five main theories: namely, Leader-Member Exchange Theory (LMX), Transactional Leadership, Charismatic Leadership, Transformational Leadership, and Innovation Leadership approach. The main purpose of this research is to determine the attributes of innovation leadership. The study will provide the insights of new attributions for successful innovation leadership.

\section{Contemporary Leadership Theories}

\subsection{Leader-Member Exchange}

Leader-member exchange theory (LMX) views leadership as a process, bringing into focus the interactive relations between the leader and the follower, with particular stress on the pair's communication process (Gardner, 1990; Northouse, 2004). According to Northouse (2004), LMX theory is concerned with the follower, the leader and the dyadic relationship between them; it provides a description and prescription of the relationship between the leader and followers working in the organization. LMX describes how individuals develop leadership connections across the organization for the effective accomplishment of their work (Northouse, 2004).

However, these connections can lead to the creation of petty biases among subordinates and leaders; such relationships may function against the human value of fairness which could lead to charges of discrimination against individuals of different genders, ages and cultures. However, as Northouse acknowledges, the idea behind LMX is not completely developed; it has failed to fully specify the relationship at higher moral leadermember exchanges. There have also been queries on its content validity; that is to say, it may not measure what it is supposed to measure (Nahavandi, 2009).

\subsection{Transactional Leadership}

This type of leadership also has its basis in the exchanges that takes place between leaders and followers (Avolio, Bass, \& Jung, 1999). In this perspective, the leader provides encouragement to his or her followers to succeed in their responsibilities through the resources and rewards the leader dispenses in exchange for the followers' motivation, productivity and task achievement (Barbuto, 2005; Nahavandi, 2009). The theory suggests that, when the work environment of the follower does not provide the necessary motivation, direction and satisfaction, the leader will make available compensation for the follower's experienced deficiencies in the organization (Den Hartog, Muijen, \& Koopman, 1997). The related contingency reward is the reward made available to followers for achieving goals. Although there are arguments supporting the effectiveness of transactional relations in achieving performance, an exclusive focus on the exchanges and transactions with followers has been criticized in the case of a) low expectations of followers and b) non-performing organizations (Banerji \& Krishnan, 2000; Barbuto, 2005; Nahavandi, 2009). A particularly strong critique is that transactional leadership fails to inspire followers to reach for excellence, and focuses on short-term, immediate outcomes rather than on long-term commitment (Nahavandi, 2009), because the work environment of the follower does not provide the necessary motivation, direction and satisfaction (Den Hartog et al., 1997).

\subsection{Charismatic Leadership}

Charisma refers to an enthusiastic, self-confident quality in a leader whose personality and actions influence people to behave in certain ways (Nahavandi, 2009). Charismatic leadership theory describes what to expect from both leaders and followers (Mittal, 2015). In an organization, charismatic leaders usually arise in a crisis or during major administrative changes to empower their followers and lead the call for organizational reform (Hinkin \& Tracey, 1999). Charismatic leaders inspire eagerness in their teams and are energetic in motivating employees to move forward (Mittal, 2015). These leaders develop special relationships with their subordinates through inspiration of the shared vision, and are characterized as going beyond goal-setting, resource use and conducting business. Subordinates consider this type of leader as a "real" leader and followers are attracted be- 
cause of the leader's personal characteristics (Kouzes \& Posner, 2003; Nahavandi, 2009; Smith, Montagno, \& Kuzmenko, 2004). Charismatic leadership is most likely to emerge during uncertain conditions in the organizational life cycle, particularly in the early and late stages when the organization is more likely to lose its direction (Hinkin \&Tracey, 1999). Nahavandi (2009) suggests that such leaders are more likely to appear in organizations that are characterized by a flexible and organic structure and a non-bureaucratic culture. Charismatic leadership is a leadership style that is identifiable, but its characteristics may be less tangible than those of other leadership styles (Bell, 2013).

\subsection{Transformational Leadership}

Transformational leaders are able to transform people from followers into leaders (van Linden \& Fertman, 1998) and to influence followers to transcend their self-interests for the greater good of the organization (Bass, 1990). Transformational leaders motivate and inspire followers to achieve extraordinary goals (Berson \& Avolio, 2004), and are process-oriented (van Linden \& Fertman, 1998). According to Banerji and Krishnan (2000), transformational leaders exploit the situation to launch and sustain the transformation process in organizations. To be able to do this, they must have the ability to articulate a compelling vision and to clarify any ambiguity that followers perceive, to ensure that everyone is following the new path. The common characteristics of authentic transformational leaders have been identified as: idealized influence, inspirational motivation, intellectual stimulation, and individualized consideration (Bass \& Avolio, 1994; Nahavandi, 2009). Avolio (1994) found that transformational leadership encourages individuals to greater moral responsibility by motivating them for the good of the organization (Den Hartog et al., 1997).

Previous discussions on leadership theories have indicated strong support for transformational leadership and charismatic leadership in enhancing organizational performance (Mittal, 2015). These two theories envisage forward looking leaders who are able to foster innovation, motivate employees to performance beyond normal expectations, and establish core values where employees put aside their personal interests for the greater good of the organization (Samad, 2012). However, organization performance and achieving the goals of an organization require leaders who are also innovative (Samad, 2011). This implies that the characteristics of transformational leadership and charismatic leadership are still inadequate to achieve organizational excellence, particularly in the face of ongoing rapid changes in technology and globalization. Research by Devinneyet al., (2001), for example, concluded that the greater the amount of innovation within an organization, the greater its market and financial performance. A recent study by Miller et al., (2012) supports this conclusion and identifies the critical organizational innovation elements that differentiate effective leaders from ineffective leaders, including an explicit investment in innovation strategy, innovation governance, and innovation leadership (Shavinina, 2011), elements which are not emphasised in the charismatic and transformational leadership models (Samad, 2012). According to Porter and Malloch (2010) innovation leadership is necessary to analyse and synthesize the impact of the dramatic changes in the organization and to achieve sustainable performance. Thus new attributes for leaders are required for meeting the increasing demands for innovation in many facets of organizations. Research findings suggest that the behaviours of innovative leaders are different from those of other leadership behaviours that have been deemed to be sufficient in conventional leadership development initiatives (Hamel \& Labarre, 2011; Teece, 2009). This is backed up by Parker and Bradley (2000), who stated that innovation leadership is greatly needed in an organization so that the organization can be flexible, adaptive, entrepreneurial, as well as innovative, to effectively meet the changing demands of today's business environment. Hence, it is suggested that there is a research gap-an absence of empirical studies that identify successful innovation leaders.

\subsection{Innovation Leadership Approach}

Innovation leadership proposesthat leaders play a multitude of roles when facilitating innovation in organizations, especially roles that influence creativity and innovation. With the appropriate leadership, successful innovation becomes a realistic and achievable goal; however, without it, the challenge may prove insurmountable (Hunter \& Cushenbery, 2011). Organizations that actively pursue excellence require support from the organizational hierarchy, and a culture that values and nurtures creativity (Horth \& Vehar, 2012), considerable resources and a deliberate focus on innovation. Innovation leaders are those managers, executives or entrepreneurswhatever their functions or positions-who successfully initiate, sponsor, and steer innovation in their organizations (Deschamps, 2003). 
The term "innovation" is often used interchangeably with other terms, such as new or novel idea, radical, change, and creativity (Waples, Friedrich, \& Shelton, 2011). Organizational success requires innovation leaders who can inspire a mind-set that opens an organization to discovery; and the development of the framework that supports an innovation strategy and empowers people to make the right choices (Stevenson, 2012). As Horth and Vehar (2012) explain, innovation can be a "new-look" or a "re-look", but both require innovation leadership. Innovation leadership is a process of creating the direction, alignment, and commitment that is needed to create and implement something new that adds value to an organization. Hence, innovation leadership is about being able to form an integrated overview of innovation and, at the same time, lead the components of innovation in a strategic manner (Ailin \& Lindgren, 2008). Thus, innovation leadership is not the management of an innovative product development project; rather, it is the process of leading the company's innovation portfolio strategically. Specifically, innovation leadership is vital for consistent superior organizational performance (Samad et al., 2015).

Innovation leadership is defined as the process of creating the context for innovation to occur; creating and implementing the roles, decision-making structures, physical space, partnerships, networks, and equipment that support innovative thinking and testing (Porter \& Malloch, 2010). Adjei (2013) defined innovation leadership as the synthesis of different leadership styles in organizations to influence employees to produce creative ideas, products, services and solutions. According to Adjei, because innovation leadership is a complex concept, there is no single explanation or formula for a leader to follow to increase innovation.

Further consideration of innovation leadership is important to improve the body of behavioural leadership theories, which mainly stress only the capability of individuals or leaders (Adjei, 2013). Hence, in line with the definition given by Van de Ven and Chu (1989), innovation leadership encompasses the encouragement of individual initiatives, clarification of individual responsibilities, provision of clear and complete performance evaluation feedback, a strong task orientation, emphasis on quality group relationships and trust in organizational members.

\section{Innovation Leadership Models}

Horth and Vehar (2012) have suggested that innovation leadership is constituted from three broad areas: 1) a tool set: the collection of tools and techniques used to generate new options, implement them in the organization, communicate direction, create alignment, and cause commitment; 2) a skill set: a framework that allows innovation leaders to use their knowledge and abilities to accomplish their goals. More than tools and techniques, it requires facility, practice, and mastery of processes; and 3) a mind set: the attitudes and resulting behaviours that allow the tools and skills to be effective. The mind-set is the fundamental operating system of the creative thinker and it distinguishes those leaders who enable creative thinking and innovation from those who stifle it.

Roscorla (2010) proposed that innovative leadership should incorporate the following behaviours: 1) Embrace a challenge; 2) Drive change through collective creativity and knowledge; 3) Shape the culture of the organization; 4) Establish a professional learning system; 5) Decide and systematize; 6) Ensure digital access and infrastructure; and 7) Demand accountability. On the other hand, Lindgren and Abdullah (2013) have proposed a five-element innovation leadership model for a company to effectively implement innovation leadership. The elements to consider are: 1) The task of innovation leadership; 2) The field of innovation leadership, 3) The success criteria for the company's innovation leadership task; 4) The model of innovation leadership used in the company and 5) The process of innovation leadership.

In addition, Shavinina (2011) proposed a model of internal structure of individual innovation leadership based on the individual at five levels. The theory explores a significant issue necessary for understanding the nature of innovation leadership, namely: "How does it happen that some individuals become innovation leaders while others do not?” Shavinina's theory argues that to successfully address this question, mainly psychological mechanisms should be taken into account, specifically the developmental and cognitive processes. The theory explains 1) A developmental foundation of innovation leadership; 2) The cognitive basis of innovation leadership; 3) Intellectual manifestations of innovation leadership; 4) Metacognitive manifestations of innovation leadership; and 5) Extra cognitive manifestations of innovation leadership. They constitute the first, second, third, fourth, and fifth levels, respectively, of the internal structure of individual innovation leadership. The study of innovation leadership has attracted more attention in recent decades and has become a new area of study to contend with the complexities of value creation (Shavinina, 2011).

Carmeli, Gelbard, and Gefen (2010) studied the importance of innovation leadership on organizational per- 
formance. The researchers had adopted innovation leadership behaviours from the Minnesota Innovation Institute, which proposed six leadership behaviours as follows: 1) Encouraging individual initiative; 2) Clarifying individual responsibilities; 3) Providing clear and complete performance evaluation feedback; 4) Maintaining a strong task orientation, 5) Emphasizing group relationships and, 6) Demonstrating trust in organizational members.

Vlok (2012) also suggested an innovation leadership profile based on competencies of innovation leaders, that is: 1) strategist, 2) capacity builder, 3) match maker and 4) achiever. Vlok's (2012) findings concluded that the model provided a coherent profile of innovation leadership competencies rather than being just another contribution at individual element or specific discipline level. Vlok's competencies were derived from observations of successful innovation leaders in practice. The profile is descriptive enough to serve as an assessment framework for leadership development, but it provides opportunities for further refinement and validation. Further research on the profile will contribute tothe professionalization of the innovation leadership discipline.

\section{Discussion}

Empirically, the effectiveness of a charismatic, transformational and innovative leadership on organizational performance has already been established. For instance, charismatic and transformational leadership have been shown to be positively related to performance in the US and North American organizations (see, for example, Bass, 1990; LeBrasseur et al., 2002; Mekraz, 2011), in Korean companies (Jung \& Sosik, 2002), and in Taiwanese organizations (Liaw et al., 2008). Such leadership is important for performance in the private sector (e.g. Hater \& Bass, 1988; Yammarino \& Dubinsky, 1994), the educational sector (e.g. Harvey, Lins, \& Roper, 2004), in non-profit organizations (e.g. Bass, Avolio, Jung, \& Berson, 2003), and in the government sector (Goodwin, Wofford, \& Whittington, 2001).

The literature shows that transformational leadership increases the effectiveness of the strategic planning role in enhancing the organization's performance (Goodwin et al., 2001; LeBrasseur et al., 2002; Mekraz, 2011). Samad and Abdullah (2012) found that transformational leadership played a significant role in the organizational performance of logistics companies in Malaysia. Samad et al., (2015) in their model of organizational performance, have proposed the role of leadership as the moderator in the relationship between strategic planning and organizational performance. This is consistent with Sherman et al., (2006), who suggested that, to strengthen the relationship between strategic planning and organizational performance, certain variables must be integrated in the relationship; Among these variables are organizational culture, organizational contextual factors, organizational strategy, and leadership. This underscores the importance of leadership as a key moderator variable in the strategy- performance relationship.

Innovation leadership has been explored in creativity research (Mumford, Scott, Gaddis, \& Strange, 2002; Redmond, Mumford, \& Teach, 1993). It has also been studied from various perspectives (Van de Ven \& Chu, 1989), including from the perspective of entrepreneurial research (Gupta, MacMillan, \& Surie, 2004; McGrath \& MacMillan, 2000). All these studies indicate that innovation leadership promotes and supports an exploratory orientation by cultivating a context for change and adaptation among organizational members (Christensen, 2013; Hammer \& Champy, 2009; Van de Ven \& Chu, 1989) which usually result in enhanced organizational performance (Carmeli et al., 2010). Deschamps’ (2003) research on innovation leadership has revealed that innovative leaders are very interested in and receptive to new ideas proposed by their colleagues and subordinates, and this can potentially lead to new products, services and processes and, ultimately, can improve organizational performance (Horth \& Vehar, 2012). Carmeli et al., (2010) examined the role of innovation leadership in cultivating the strategic fit of the organization with its environment, and enhancing various economic relationships and product performance outcomes. Their findings reveal that innovation leadership is an important factor that significantly enhanced firm performance.

Vlok (2012), who proposed innovation leadership competencies, suggests that there is a knowledge gap related to which innovative competencies might be critical for successful leadership to take place. This was also raised by Deschamps (2003), who stressed that the contemporary literature and research on innovation provided a fragmented picture of innovation and leadership. Therefore, Vlok argues, there should be a specific focus on the combination of innovation and leadership, or on the strategic role that innovation leadership plays in companies (2012). Carmeli, Gelbard, and Gefen (2010) investigated the role innovation leadership in cultivating the strategic fit of the organization with its environment, and enhancing various economic relationships and product performance outcomes. The results indicated that innovation leadership significantly enhanced firm perform- 
ance.

The preceding discussions have examined the concepts, models, theories and rationale for innovation leadership. The arguments are persuasive and widely applied in organizational research, especially in relation to charismatic and transformational leadership. For example, transformational leadership theory has been widely studied with validated instruments, and this construct has demonstrated an empirical link to organizational excellence (Samad et al., 2015). However, a broad review of all of leadership theories demonstrates that they are incomplete without the attribute of innovation leadership. According to numerous researchers (for example, Carmeli et al., 2010; Deschamps, 2003; Horth \& Vehar 2012; Shavinina, 2011; andVlok, 2012), this element is critical for bringing about change and enhancing the performance of organizations. Shavinina (2011) has suggested that, in thelight of the ever increasing importance of innovation in contemporary society, innovation leadership should become the focus of intensive research.

It can be concluded that innovation leadership has a significant role to play in organizational performance and it adds considerably to the corpus of leadership theory. The results of the current literature review show that innovation leadership is relevant to multi-leadership attributes, and should be examined from different perspectives.

\section{Conclusion}

Although new attributes for leaders are needed to meet the increasing demands for innovation in many aspects of organizations, limited attention has been paid to identifying which specific aspects are required for a successful innovation leader.This paper has revealed that innovation leadership is relevant to multi-leadership attributes. Attributes of charismatic leadership, transformational leadership and innovation leadership are the principal precursors to innovation leadership. This clarification may provide some insights into how innovation leadership can enhance organizational performance in modern organizations. The paper's findings are of value to academics, because they provide a starting point for further research in this area. In-depth analysis of innovation leadership attributes and the development of more comprehensive innovation leadership measurements are required. In addition, future research should focus on examining the role of innovation leadership, based on multi-leadership attributes and competencies, in achieving higher levels of organizational performance and sustainability.

\section{Acknowledgements}

This paper was presented at the 2nd Academic International Conference on Business, Marketing and Management (AICBMM-2016), held in Harvard University, Boston, USA, 5-7 April 2016. The authors thank the conference participants for their comments on the paper.

\section{References}

Adjei, D. (2013). Innovation Leadership Management. International Journal of ICT and Management, 1, 103-106.

Ailin, M., \& Lindgren, P. (2008). Conceptualizing Strategic Innovation Leadership for Competitive Survival and Excellence. Journal of Knowledge Globalization, 1, 87-107.

Avolio, B. J., Bass, B. M. \&Jung, D. I. (1999). Re-Examining the Components of Transformational and Transactional Leadership Using the Mu1ltifactor Leadership. Journal of Occupational and Organizational Psychology, 72, 441-462. http://dx.doi.org/10.1348/096317999166789

Banerji, P., \& Krishnan, V. R. (2000). Ethical Preferences of Transformational Leaders: An Empirical Investigation. Leadership \& Organization Development Journal, 21, 405-413. http://dx.doi.org/10.1108/01437730010358161

Barbuto, J. E. (2005). Motivation and Transactional, Charismatic, and Transformational Leadership: A Test of Antecedents. Journal of Leadership \& Organizational Studies, 11, 26-40. http://dx.doi.org/10.1177/107179190501100403

Bass, B. M. (1990). From Transactional to Transformational Leadership : Learning to Share the Vision. Organizational Dynamics, 18, 19-32. http://dx.doi.org/10.1016/0090-2616(90)90061-S

Bass, B. M., Avolio, B. J., Jung, D. I., \& Berson, Y. (2003). Predicting Unit Performance by Assessing Transformational and Transactional Leadership. Journal of Applied Psychology, 88, 207-218. http://dx.doi.org/10.1037/0021-9010.88.2.207

Bell, R. M. (2013). Charismatic Leadership Case Study with Ronald Reagan as Exemplar. Emerging Leadership Journeys, 6 , 66-74.

Berson, Y., \& Avolio, B. J.(2004). Transformational Leadership and the Dissemination of Organizational Goals: A Case 
Study of a Telecommunication Firm. The Leadership Quarterly, 15, 625-646. http://dx.doi.org/10.1016/j.leaqua.2004.07.003

Carmeli, A., Gelbard, R., \& Gefen, D. (2010). The Importance of Innovation Leadership in Cultivating Strategic Fit and Enhancing Firm Performance. The Leadership Quarterly, 21, 339-349. http://dx.doi.org/10.1016/j.leaqua.2010.03.001

Chen, M. (2007). Entrepreneurial Leadership and New Ventures: Creativity in Entrepreneurial Teams. Creativity and Innovation Management, 16, 239-249. http://dx.doi.org/10.1111/j.1467-8691.2007.00439.x

Christensen, C. (2013). The Innovator's Dilemma: When New Technologies Cause Great Firms to Fail. Boston: Harvard Business Review Press.

Den Hartog, D. N., Muijen, J. J., \& Koopman, P. L. (1997). Transactional versus Transformational Leadership: An Analysis of the MLQ. Journal of Occupational and Organizational Psychology, 70, $19-34$. http://dx.doi.org/10.1111/j.2044-8325.1997.tb00628.x

Deschamps, J. P. (2003). Innovation and Leadership. In L. V. Shavinina (Eds.), The International Handbook on Innovation (pp. 815-834). Amsterdam: Elsevier. http://dx.doi.org/10.1016/B978-008044198-6/50056-5

Devinney, T., Midgley, D., \& Deering, A. (2001). Knowledge Management: Philosophy, Process, Pitfalls, and Performance. Sydney: Australian Graduate School of Management, University of New South Wales.

Goodwin, V. L., Wofford, J. C., \& Whittington, J. L. (2001). A Theoretical and Empirical Extension to the Transformational Leadership Construct. Journal of Organizational Behavior, 22, 759-774. http://dx.doi.org/10.1002/job.111

Gupta, V., MacMillan, I. C., \& Surie, G. (2004). Entrepreneurial Leadership: Developing and Measuring a Cross-Cultural Construct. Journal of Business Venturing, 19, 241-260. http://dx.doi.org/10.1016/S0883-9026(03)00040-5

Hamel, G., \& Labarre, P. (2011). Inventing Management 2.0. The Wall Street Journal, 17 February.

Hammer, M., \& Champy, J. (2009). Reengineering the Corporation: A Manifesto for Business Revolution. New York: Harper Business Essentials.

Harvey, C. R., Lins, K. V., \& Roper, A. H. (2004). The Effect of Capital Structure When Expected Agency Costs Are Extreme. Journal of Financial Economics, 74, 3-30. http://dx.doi.org/10.1016/j.jfineco.2003.07.003

Hater, J. J., \& Bass, B. M. (1988). Superiors’ Evaluations and Subordinates’ Perceptions of Transformational and Transactional Leadership. Journal of Applied Psychology, 73, 695-702. http://dx.doi.org/10.1037/0021-9010.73.4.695

Hinkin, T. R., \& Tracey, J. B. (1999). The Relevance of Charisma for Transformational Leadership in Stable Organizations. Journal of Organizational Change Management, 12, 105-119. http://dx.doi.org/10.1108/09534819910263659

Horth, D. M., \& Vehar, J. (2012). Becoming a Leader Who Fosters Innovation. Center for Creative Leadership.

Hunter, S. T., \& Cushenbery, L. (2011). Leading for Innovation: Direct and Indirect Influences. Advances in Developing Human Resources, 13, 248-265. http://dx.doi.org/10.1177/1523422311424263

Jung, D. I., \& Sosik, J. J. (2002). Transformational Leadership in Work Groups the Role of Empowerment, Cohesiveness, and Collective-Efficacy on Perceived Group Performance. Small Group Research, 33, 313-336. http://dx.doi.org/10.1177/10496402033003002

Kouzes, J., \& Posner, B. (2003). The Leadership Practices Inventory (LPI). San Francisco, CA: John Wiley \& Sons.

LeBrasseur, R., Whissell, R., \& Ojha, A. (2002). Organisational Learning, Transformational Leadership and Implementation of Continuous Quality Improvement in Canadian Hospitals. Australian Journal of Management, 27, 141-162. http://dx.doi.org/10.1177/031289620202700203

Liaw, J., Marshall, G., Yuan, Y., Ferreccio, C., Steinmaus, C., \&Smith, A. H. (2008). Increased Childhood Liver Cancer Mortality and Arsenic in Drinking Water in Northern Chile. Cancer Epidemiology Biomarkers \& Prevention, 17, 19821987. http://dx.doi.org/10.1158/1055-9965.EPI-07-2816

Lindgren, P., \& Abdullah, M. (2013). Conceptualizing Strategic Business Model Innovation Leadership for Business Survival and Business Model Innovation Excellence. Journal of Multi Business Model Innovation and Technology, 1, 115134.

McGrath, R. G., \& MacMillan, I. C. (2000). Assessing Technology Projects Using Real Options Reasoning. Research Technology Management, 43, 35-49.

Mekraz, A. (2011). Impacting Retail Store Performance: A Correlational Study of the Relationship between Transformational and Transactional Leadership Style and Bottom Line Performance Indicators. Doctoral Dissertation, Capella: Capella University.

Miller, P., Klokgieters, K., Brankovic, A., \& Duppen, F. (2012). Managing Innovation: An Insider Perspective. Capgemini Innovation Leadership Study.

Mittal, R. (2015). Charismatic and Transformational Leadership Styles: A Cross-Cultural Perspective. International Journal of Business and Management, 10, 26-33. http://dx.doi.org/10.5539/ijbm.v10n3p26 
Mumford, M. D., Scott, G. M., Gaddis, B., \& Strange, J. M. (2002). Leading Creative People: Orchestrating Expertise and Relationships. The Leadership Quarterly, 13, 705-750. http://dx.doi.org/10.1016/S1048-9843(02)00158-3

Nahavandi, A. (2009). The Art and Science of Leadership (pp. 103-104). Upper Saddle River, NJ: Prentice Hall.

Parker, R., \& Bradley, L. (2000). Organisational Culture in the Public Sector: Evidence from Six Organisations. International Journal of Public Sector Management, 13, 125-141. http://dx.doi.org/10.1108/09513550010338773

Porter-O’Grady, T., \& Malloch, K. (2010). Innovation Leadership: Creating the Landscape of Healthcare. Sudbury, MA: Jones \& Bartlett Learning.

Redmond, M. R., Mumford, M. D., \& Teach, R. (1993). Putting Creativity to Work: Effects of Leader Behaviour on Subordinate Creativity. Organizational Behaviour and Human Decision Processes, 55, 120-151.

http://dx.doi.org/10.1006/obhd.1993.1027

Roscorla, T. (2010). The 7 Steps to Innovative Leadership. http://www.convergemag.com/policy/The-7-Elements-of-Innovative-Leadership.html

Samad, S. (2011). Developing an Innovative Human Capital for Organizational Excellence: A Proposed Framework for Malaysian Zakat Institutions (Mzi). The World Universities 1st Zakat Conference, PWTC, Kuala Lumpur, 24-26 November 2011.

Samad, S. (2012). Examining the Predictors of Employee Work Outcomes—Case Study in Logistics Companies. Journal of Advances in Natural and Applied Sciences, ANAS, 6, 723-730.

Samad, S., \& Abdullah, Z. (2012). The Influence of Leadership Styles on Organizational Performance of Logistics Companies. International Business Management, 6, 378-383. http://dx.doi.org/10.3923/ibm.2012.374.383

Samad, S., Yusuf, S., Ahmed, W., \& Yakub, M. (2015). Modelling Strategic Planning, Transformational Leadership and Organizational Performance: The Integration of Strategic Management Theories. Australian Journal of Basic and Applied Sciences, 9, 94-99.

Sattayaraksa, T., \& Boon-Itt, S. (2012). Leadership as a Determinant of Product Innovation: A Systematic Review of the Literature. IEEE International Conference on Industrial Engineering and Engineering Management, Hong Kong, 10-13 December 2012, 677-682. http://dx.doi.org/10.1109/ieem.2012.6837825

Seltzer, J., \& Bass, B. M. (1990). Transformational Leadership: Beyond Initiation and Consideration. Journal of Management, 16, 693-703. http://dx.doi.org/10.1177/014920639001600403

Senior, B., \& Fleming, J. (2006). Organizational Change. London: Prentice Hall.

Shavinina, L. V. (2011). Discovering a Unique Talent: On the Nature of Individual Innovation Leadership. Talent Development \& Excellence, 3, 165-185.

Sherman, H., Rowley, D. J., \& Armandi, B. R. (2006). Strategic Management: An Organization Change Approach. Oxford: University Press of America.

Smith, B. N., Montagno, R. V., \& Kuzmenko, T. N. (2004). Transformational and Servant Leadership: Content and Contextual Comparisons. Journal of Leadership \& Organizational Studies, 10, 80-91. http://dx.doi.org/10.1177/107179190401000406

Stevenson, J. E. (2012). Breaking Away-A New Model for Innovation Leadership. Employment Relations Today, 39 , 17-25. http://dx.doi.org/10.1002/ert.21361

Teece, D. (2009). Managing Intellectual Capital, Organizational, Strategic and Policy Dimensions. New York: Oxford Press.

Van Linden, J. A., \& Fertman, C. I. (1998). Youth Leadership: A Guide to Understanding Leadership Development in Adolescents. San Francisco, CA: Jossey-Bass.

Vlok, A. (2012). A Leadership Competency Profile for Innovation Leaders in a Science-Based Research and Innovation Organization in South Africa. Procedia-Social and Behavioural Sciences, 41, 209-226. http://dx.doi.org/10.1002/ert.21361

Waples, E. P., Friedrich, T. L., \& Shelton, P. M. (2011). Closing Comments on “Leading for Innovation”: We’ve Only Just Begun. Advances in Developing Human Resources, 13, 406-413. http://dx.doi.org/10.1177/1523422311424719

Yammarino, F. J., \& Dubinsky, A. J. (1994). Transformational Leadership Theory: Using Levels of Analysis to Determine Boundary Conditions. Personnel Psychology, 47, 787-811. http://dx.doi.org/10.1111/j.1744-6570.1994.tb01576.x 